\title{
AN EXPERIMENTAL STUDY OF METHODS FOR BRIDGING NERVE DEFECTS
}

\author{
WITH A DESCRIPTION OF A NEW METHOD OF AUTOTRANSPLANT \\ (AUTO-AUTOTRANSPLANT) \\ ERNEST SACHS, M.D. \\ Professor of Clinical Neurologic Surgery, Washington University \\ School of Medicine \\ AND \\ JULIAN Y. MALONE, M.D. \\ Intern in Surgery, Barnes Hospital; Fellow in Neurologic Surgery, \\ Washington University School of Medicine \\ ST, LOUIS
}

I. Introduction.

Object.

II. Methods used in this research.

1. Technic used in repair.

2. Methods of repair.

3. Testing physiologically.

4. Anatomic methods.

III. Results with different types.

Type 1. Histologic results.

Physiologic results.

Type 2. Histologic results.

Physiologic results.

Type 3. Histologic results.

Physiologic results.

IV. Discussion of merits of different methods.

V. General considerations.

VI. Summary.

\section{INTRODUCTION}

In 1918 one of us found that, after removing a tumor of the ulnar nerve, there was such a large gap that it was impossible even by transplanting the nerve into a new bed and flexing the arm to get the two ends together. He, therefore, implanted the central and peripheral ends into longitudinal slits in the median nerve with the idea of using the nerve as a bridge. The nerve regenerated perfectly.

The research herewith reported was undertaken to determine the best method of repairing an injured peripheral nerve when an end-toend suture was not possible. The advantage of a cable autotransplant as compared with a homotransplant or heterotransplant has been so 
completely worked out by $\mathrm{Huber}^{1}$ and his co-workers that we saw no purpose in repeating their work. We saw certain possible objections, however, to this method which prompted us to investigate other methods for bridging defects in peripheral nerves. Our experiments have been carried on over a period of two years. The cases were studied both anatomically and physiologically.

We will not discuss the literature on this subject. The most important work bearing on this subject has been done by Huber, ${ }^{2}$ Howell and Huber, ${ }^{3}$ Joyce, ${ }^{4}$ Kilvington, ${ }^{5}$ Osborne and Kilvington, ${ }^{6}$ Kirk and Lewis, ${ }^{7}$ Langley and Hashimotto, ${ }^{8}$ Ranson, ${ }^{9}$ Spiller, Frazier and Van Kaathoven, ${ }^{10}$ and Von Hofmeister. ${ }^{11}$

\section{METHODS USED IN THIS RESEARCH}

1. Technic.-Dogs were used for all the experiments. The animals were always operated on under general anesthesia. In each case the sciatic nerve and its branches were used. Care was taken to have a bloodless field, to handle the nerves as little as possible and then only by the perineural sheath. The nerves were cut with a razor blade and handled with fine mouse tooth forceps. The sutures throughout were of silk, either blood vessel silk or one strand of split No. A silk, threaded on a No. 10 cambric needle. The sutures were passed only through the perineural sheath. Bleeding from the cut end of the nerve

1. Huber, G. C.: Repair of Peripheral Nerve Injuries, Surg., Gynec. \& Obst. 30:464 (May) 1920.

2. Huber, G. C.: A Study of the Operative Treatment for Loss of Nerve Substance in Peripheral Nerves, J. Morphol. 11:630-733, 1895.

3. Howell and Huber: A Physiologica1, Histological and Clinical Study of the Degeneration and Regeneration in Peripheral Nerve Fibers After Severance of Their Connection with the Nerve Centers, J. Physiol. 13:335, 1892; ibid. 14:1, 1893

4. Joyce, J. L.: A Study of a Series of Peripheral Nerve Injuries from a Surgical Aspect, Brit. J. Surg. 6:418 (Jan.) 1919.

5. Kilvington, B.: An Investigation on the Regeneration of Nerves, Brit. M. J. 1:935 (April) 1905.

6. Osborne and Kilvington: Central Nervous Response to Peripheral Nervous. Distortion, Brain 33:289, 1911.

7. Kirk, E. G., and Lewis, Dean: Regeneration in Peripheral Nerves, Bull. Johns Hopkins Hosp. 28:71 (Feb.) 1917.

8. Langley and Hashimotto: On the Suture of Separate Nerve Bundles in a Nerve Trunk and on Internal Nerve Plexuses, J. Physiol. 51:318, 1917.

9. Ranson, S. W.: Degeneration and Regeneration of Nerve Fibers, J. Comp. Neurol. 22:487, 1912.

10. Spiller, W. G.; Frazier, C. H., and Van Kaathoven, J. J. A.: Nerve Transplantation in Treatment of Cerebral, Spinal and Peripheral Nerve Palsies, Am. J. Med. Sc. 131:430, 1906.

11. Von Hofmeister: Ueber doppelte und mehrfache Nervenpfropfung, Beitr. z. klin. Chir. 96:329, 1915. 
was controlled either by cotton pledgets soaked in warm saline or by the injection of warm saline into the nerve. Nerve tissue was always approximated to nerve tissue, and all foreign material as far as possible was kept out of the path of the regenerating fibers.

In many experiments absolute alcohol was injected into the end of the nerve to determine its effect on the various types of repair and neuroma formation.

2. Methods of Repair.-A number of different methods were tried, such as tubes of foreign bodies and of fascia, but all were discarded except the three following:

(a) Anastomosis of the central and peripheral ends of an injured nerce into longitudinal incisions in a normal nerve. These longitudinal

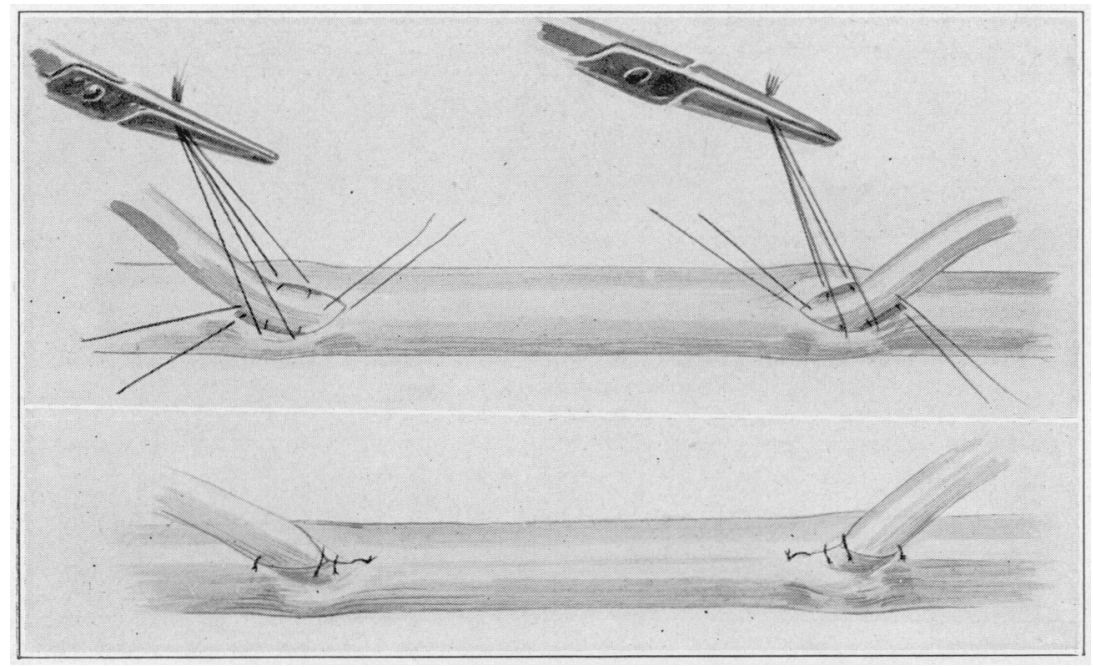

Fig. 1.-Anastomosis of the central and peripheral ends of an injured nerve into longitudinal incisions in a normal nerve.

incisions were each about $6 \mathrm{~mm}$. long and as nearly as possible in the same quadrant of the nerve. When the nerve to be implanted had a neuroma on its end from a previous operation, it was cut back until normal looking axis cylinders were exposed. The ends of the nerve were then sutured into the longitudinal slits and held in place by sutures passed through the perineural sheaths. This type of suture is illustrated in Figure 1. The peroneal nerve was cut and sutured into the tibial nerve in each case (eighteen experiments).

(b) Anastomosis of the central and peripheral ends of an injured nerve to flaps cut in the same quadrant of a normal nerve (Fig. 2). The peroneal nerve was cut and sutured to flaps in the tibial nerve. Three sutures were used at each line of suture (fifteen experiments). 


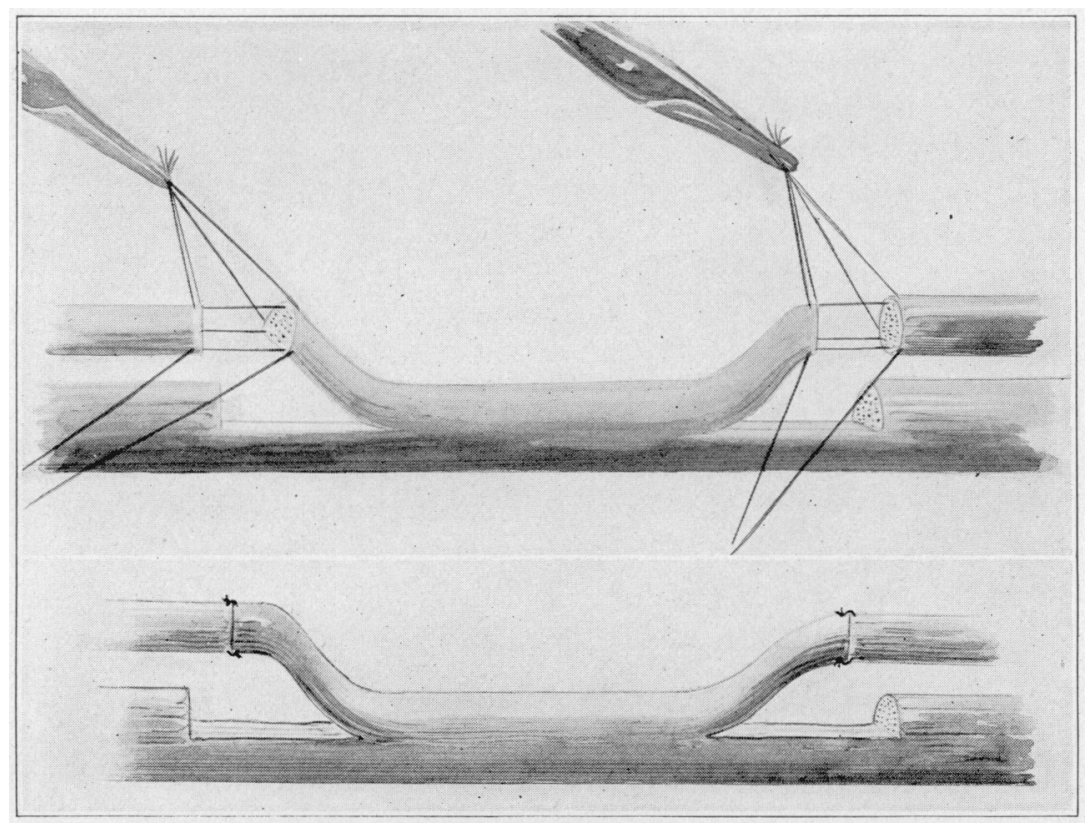

Fig. 2.-Anastomosis of the central and peripheral ends of an injured nerve to flaps cut in the same quadrant of a normal nerve.

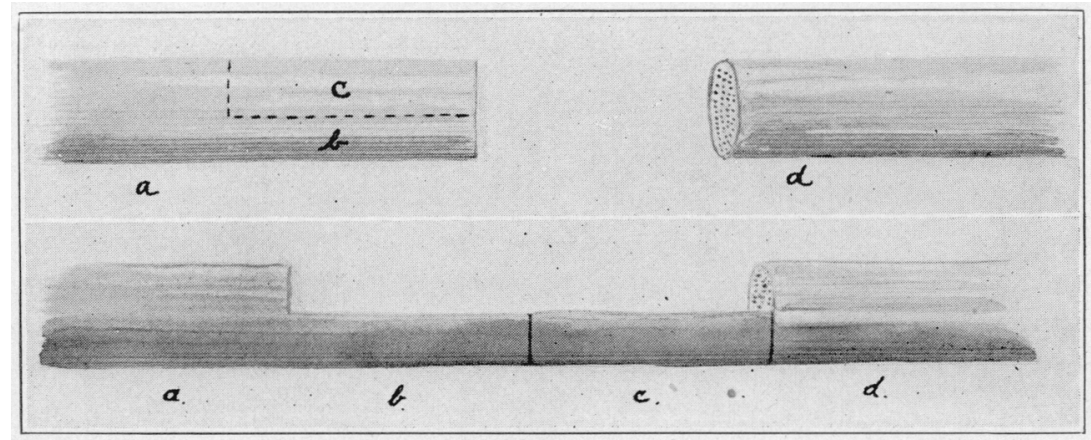

Fig. 3.-Autotransplant of half of the central end of the injured nerve, the removed segment being just long enough to bridge the defect. Portion $C$ is completely excised. 
(c) Autotransplant of half of the central end of the injured nerve, the segment remoi'ed bcing just long enough to bridge the defect (autoautotransplant) (Fig. 3). From three to four sutures were used at each suture line (sixteen experiments). A few end-to-end sutures and a few cable autotransplants were performed as controls.

In three experiments the nerve was cut and allowed to fall back into its former bed without any attempt to bring the ends together. In two of these experiments absolute alcohol was injected into the central end to test its influence upon neuroma formation.

3. Physiologic Tests.-Following the operations the nerves were exposed at varying intervals, ranging from three days to five months, and tested physiologically to determine any signs of regeneration. The animals were always anesthetized for these tests. The tests consisted of stimulating the nerve centrally and peripherally to the point of repair with small platinum e'ectrodes attached to a faradic coil. A current just strong enough (threshold current) to cause a response in a normal nerve was used. The nerve during the stimulation was raised from its bed so that it was separated from all surrounding tissues to avoid spread of the current. Two responses were looked for: a peripheral one which consisted of contractions of the muscles, and a central one which consisted in the reflex stimulation of respiration recently described by one of us (Malone). ${ }^{12}$ In the accompanying tables these two types of response are referred to as peripheral and central response.

In some cases each muscular branch of a nerve was isolated and muscular contractions were noted when each of these nerve branches was stimulated. In a few experiments, chronomyometer ${ }^{13}$ tests were applied to the muscles before the nerve was exposed.

4. Anatomic Methods.-Following the physiologic tests the animals were killed and the gross appearance of the nerve noted. The nerve was then removed; a diagram was made of it; it was stained in silver pyridin ${ }^{9}$ and examined microscopically. Some of the specimens were cut from 5 to 10 microns thick in cross-section, others longitudinally. Every fifth section was mounted so that nerve fibers could be traced systematically and these series of slides enabled us to visualize the reconstructed nerve. A few series were stained with Marchi, cut longitudinally and studied serially.

12. Malone, J. Y.: A Method of Determining the Early Regeneration of Nerve Fibers at Operation, Arch. Surg. 3:634 (Nov.) 1921.

13. Sachs, E., and Malone, J. Y.: A More Accurate Clinical Method of Diagnosis of Peripheral Nerve Lesions and of Determining the Early Recovery of a Degenerated Nerve with Report of Cases and Experimental Data, Arch. Neurol. \& Psychiat. 7:58 (Jan.) 1922. 


\section{RESULTS WITH DIFFERENT TYPES OF REPAIR}

In Table 1 are summarized the results of the eighteen experiments in which the two ends of the nerve were implanted into an adjacent nerve. The results in this type of experiment may be considered under two headings, physiologic and histologic.

(1) Physiologic-- (a) The distance from the point of anastomosis to the muscles innervated by the injured nerve was from 10 to $14 \mathrm{~cm}$. Regeneration was complete as indicated by the muscular response in every case by the ninetieth day. This would make the average rate of regeneration approximately $1 \mathrm{~cm}$. per week. Though the nerve has a normal physiologic response at the end of ninety days, histologically, it does not have the appearance of a normal nerve. The clear spaces about the axis cylinders that are seen in a normal nerve are not present; instead, this space appears filled by a pale greenish staining homogeneous mass in the silver pyridin specimens. We presume this substance is preformed myelin.

(b) Complete regeneration occurred irrespective of the distance between the two ends of the implanted nerve. This distance varied from 1 to $6 \mathrm{~cm}$. When the distance between the two ends was from 1 to $2 \mathrm{~cm}$., regeneration seemed to occur a week or two sooner than when the interval was from 5 to $6 \mathrm{~cm}$. The explanation for this observation is not perfectly clear. It may be that the number of fibers growing from the normal nerve into the implanted nerve are not sufficient to give an early reaction or it may be that the fibers growing from the central end of the injured nerve do not reach the peripheral end so soon. The latter is just what one would expect, for they have from 3 to $4 \mathrm{~cm}$. farther to grow.

(c) Regeneration occurs almost as rapidly in cases of secondary sutures performed two months after an injury as in those performed immediately after an injury.

(d) In experiments in which the distance between the central and peripheral ends of the implanted peroneal nerve was but from 1 to 2 $\mathrm{cm}$. and in which complete regeneration had occurred, stimulation of the central end of the peroneal nerve produced good contractions of the muscles innervated normally by the peroneal nerve and often a weak contraction of a muscle innervated by the tibial nerve. The longer the gap, however, the more frequently did muscles contract which were supplied by the tibial nerve, in addition to those supplied by the peroneal nerve. This indicated clearly that some peroneal fibers had grown down the tibial nerve as well as down the peroneal. In order to prove this positively, the following experiment was tried. After complete physiologic recovery had occurred in one of the implants of the peroneal nerve into the tibial nerve, the tibial nerve proximal to the implantation 


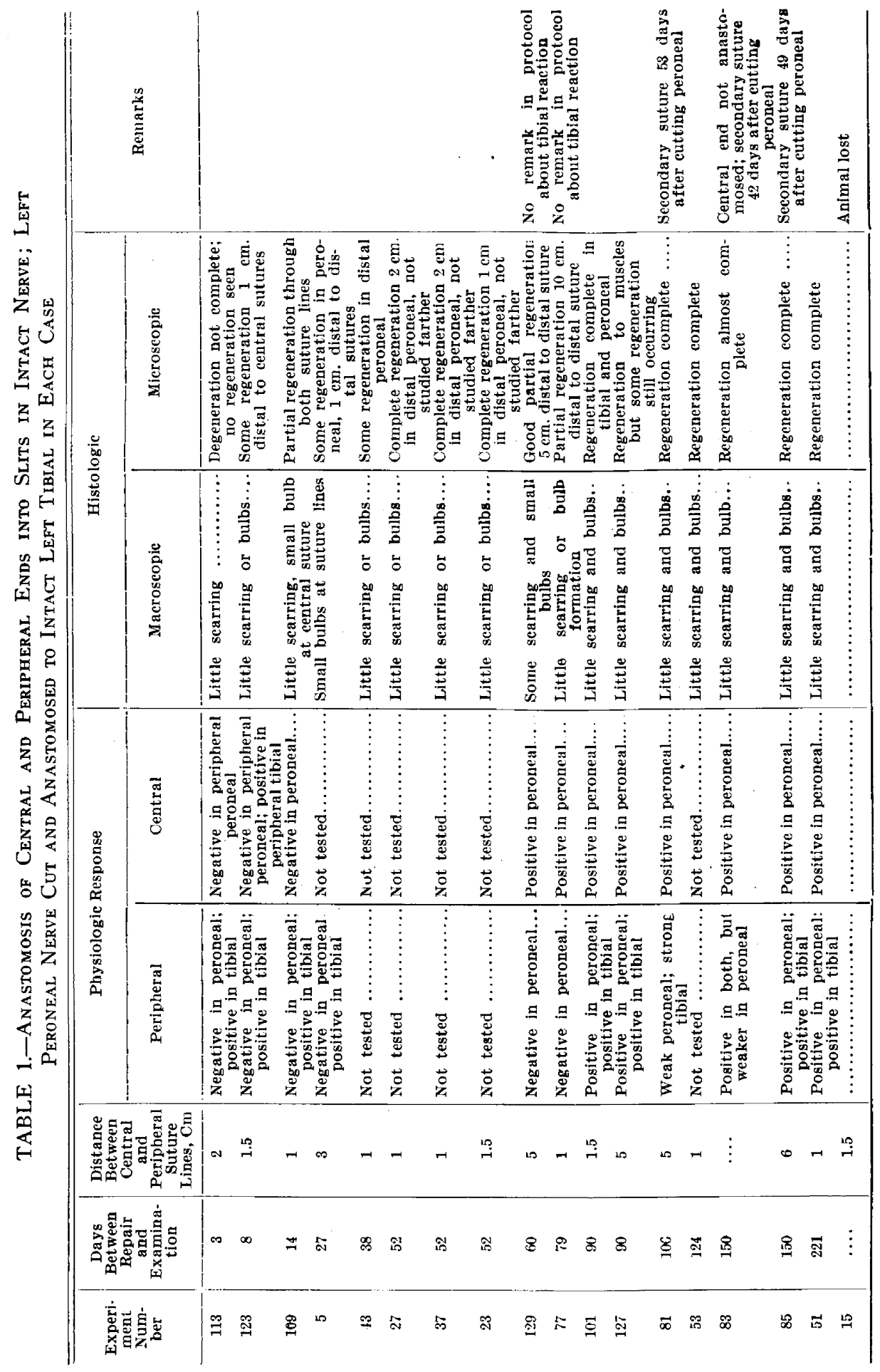


of the peroneal nerve was cut. After eighteen dass, tests were made and it was found that the peroneal muscles responded actively while the muscles supplied by the tibial nerve aloo responded, but weakly. This physiologic evidence indicated that some peroneal fibers had grown down the tibial nerve. This was confirmed histologically for sections

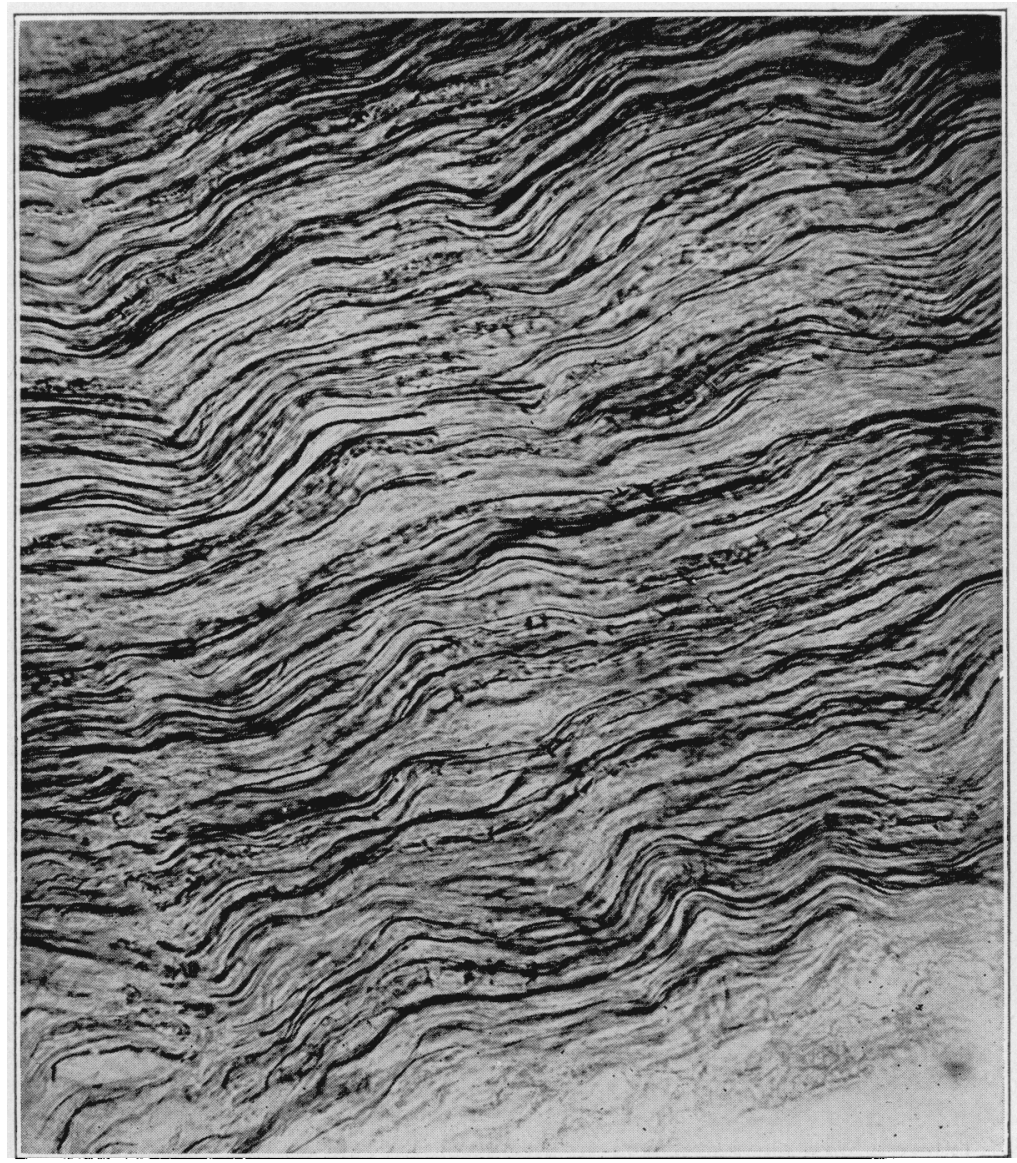

Fig. 4--Longitudinal section of peroncal nerve peripheral to implantation, showing large number of axis cylinciers.

of the peroneal nerve showed a nearly normal number of axis cylinders (Fig. 4), while the tibial nerve showed but a few axis cylinders (Fig. 5).

(c) Stimulation of the tibial nerve central to the peroneal anastomosis produced strong contractions of the tibial group of muscles and weak contractions of the peroneal group. From this and the foregoing observation, it is apparent that fibers grew from the tibial into the peroneal and vice versa. 
In order to demonstrate that complete regeneration had occurred to every muscle, the various branches of the tibial and peroneal nerves were isolated and stimulated. The muscles responded junt as vigorously, irrespective of the origin of their nerve supply.

(f) In all cases in which a muscle contaction occurred, the respiratory response described by one of us recently i.Y.M.) was also present. This respiratory response was also present in all cases in which the axis cylinders hat grown through the nerve block. even though the fibers had not yet grown down to the muscles.

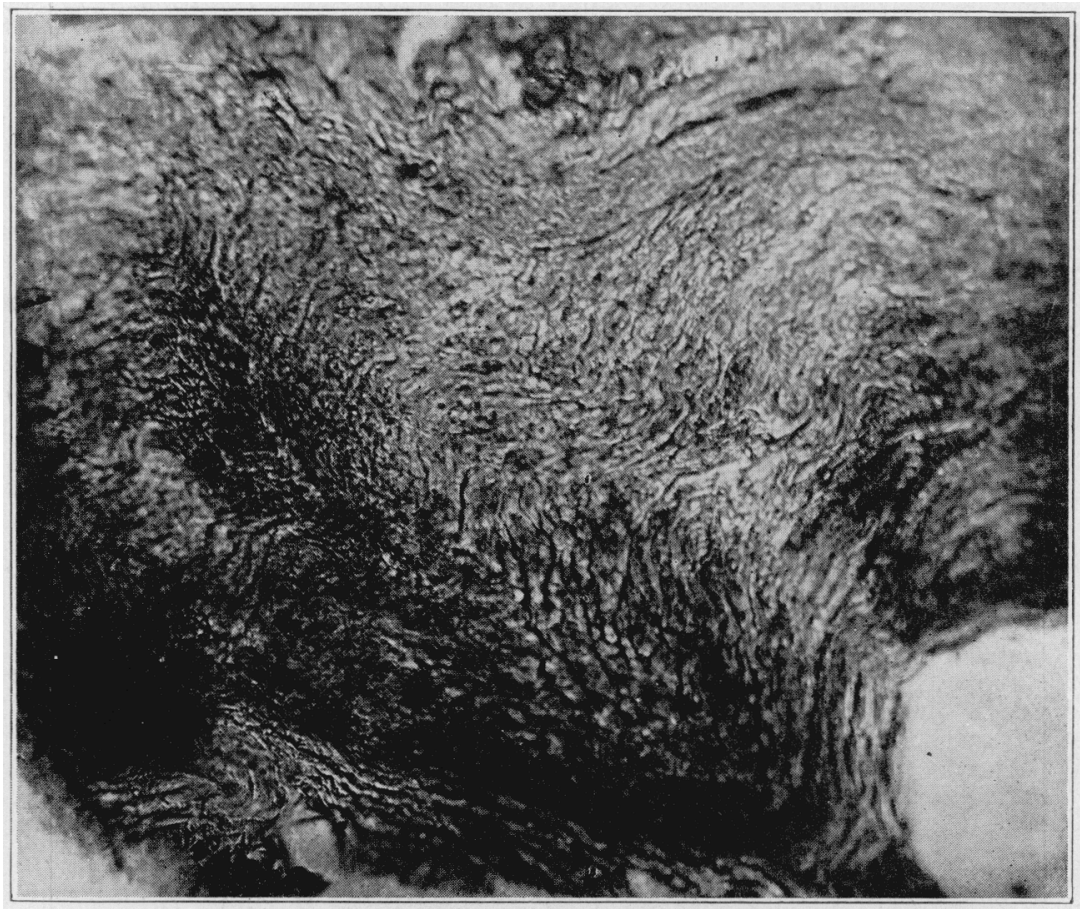

Fig. 5... Longitudinal section of tibial nerve peripheral to anastomosis show ing very few axis cylinders. Figures 4 and 5 are from a case of double implantation of peroneal nerve into tibial nerve; complete regeneration at end of tive months; tibial nerve cut central to anastomosis eighteen days before specimen removed; all filsers in Figures 4 and 5 that did not degenerate must have had their origin from the central end of the peroneal nerve.

2. Histologic.--It is difficult to trace funiculi down a nerve; but this can be done quile satisfactorily in serial sections. The difficulty arises from the fact that at every suture line the fibers form whorls, especiatly at the central point of anastomosis. We have found, however, that peroneal fibers grew down the tibial nerve (Fig. 6): and when they reach the point where the distal end of the peroneal nerve had been 
implanted. some filsers grew ino the tibial and some into the peronea! nerves. By the study of wmic acid preparations, it was posible to trace fibers from the central end of the peroneal nerve hrough the tibial nerve out into the peroneal nerve. The longer the gatp between the two encts of the peroneat nerve. the more do tibial fibers grow into the peripheral peroneal. This we believe is explained by the fact that they are "the first on the ground," that in they ariginate from the injury of the tibial nerve at the distal implanation of the peroneal and

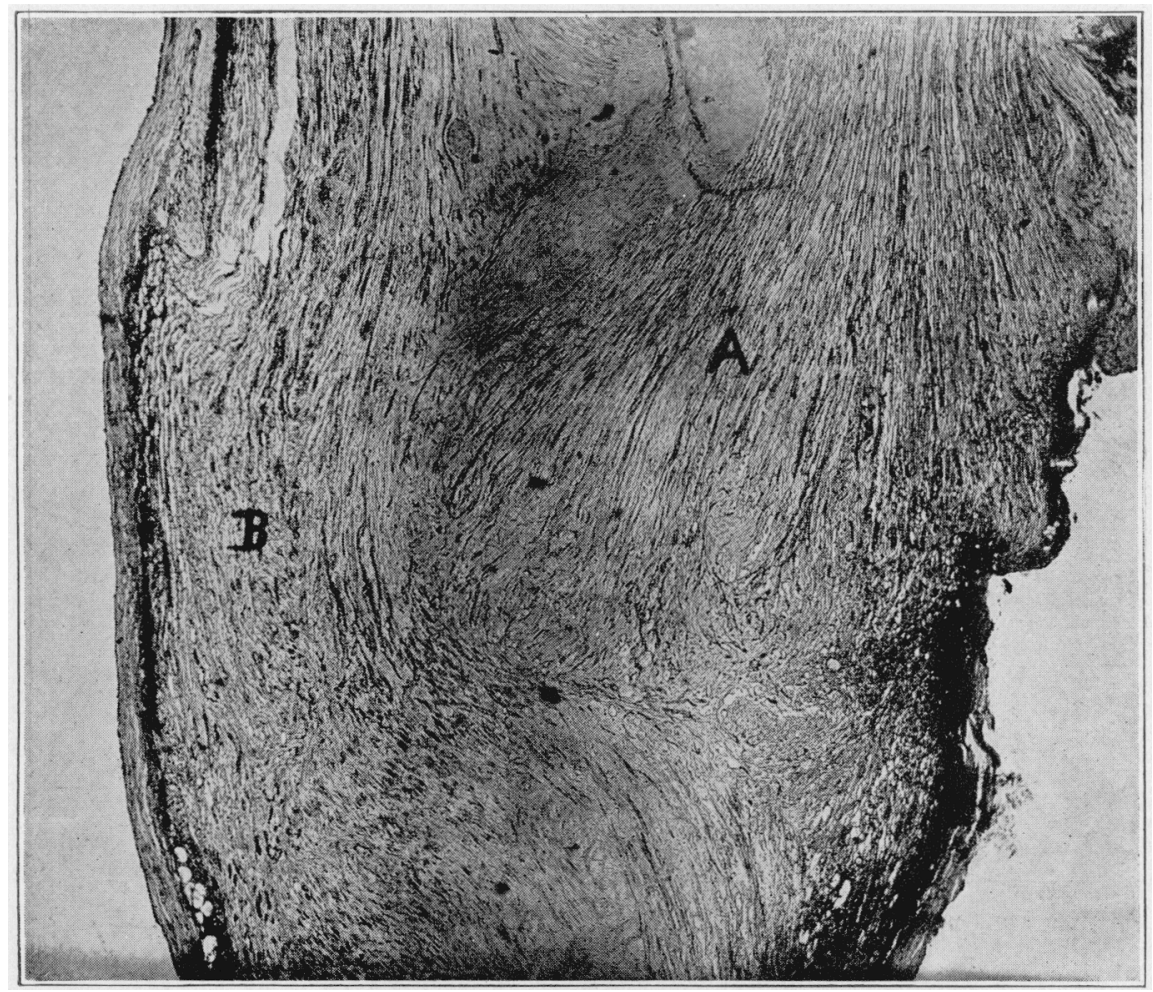

Fig. 6.-Point of anastomosis where the central end of the peroneal nerve (A) was implanted into the tilial nerve $(B)$.

have filled up many of the axis cylinder spaces hefore the fibers from the central peroneal nerve get there.

At the point of suture, axons are seen pasing into tuniculi anri also between them. There are far more axoms at the point of anastomosis than in the normal nerve above the site of andatomosis, and grossly the nerve wats larger at these points. There $i s$ also an excess of fibers distal to the anastomosis for about three months (Fig. 7); but at the end of five months (Fig. Si. the number af tibers hal been reduced to 
about normal. This overproduction of axons merely corroborates Osborne and Kilvington's "and Ranson's ${ }^{9}$ observations that the growing point of an axon may split into several fibrillae, but evidently the unused fibrillae degenerate later.

Results After Double Anastomosis to Flaps Cut into a Normal Noric.-In this series, fifteen experiments were performed (Table 2). The results were essentially the same as those in the first series and were

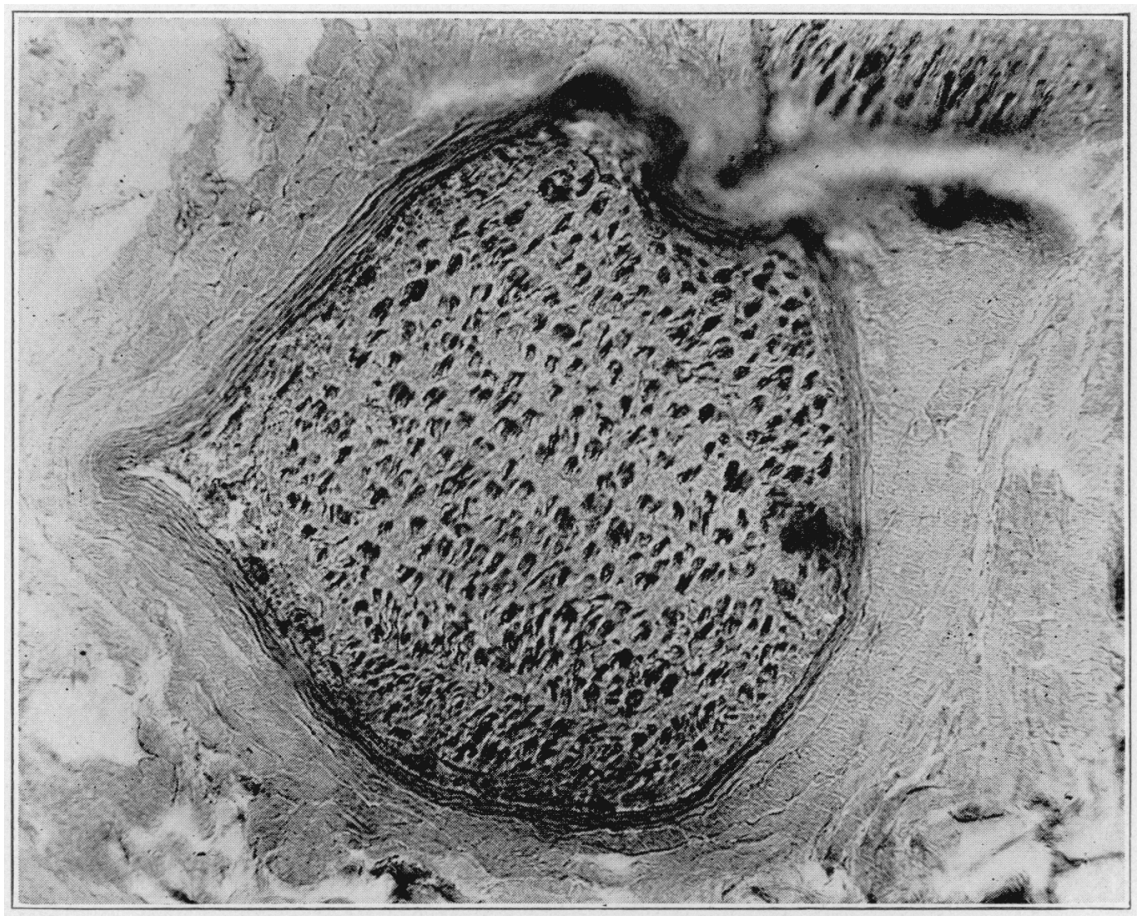

Fig. 7.-Part of peroneal nerve distal to suture showing regeneration of nerve after a double implantation at end of three months, and the excess of axis cylinders and the absence of medullary sheaths. At this stage the physiologic response of this nerve was normal; magnitication same as in Figures 8 and 9 .

about as good. There were two notalble differences. First there was more bulb formation at the site of anastomosis and more whirling of axons, but not enough evidently to interfere with regeneration; and, secondly, there was less crossing of peroneal fibers into tibial and tibial into peroneal.

Results of Autotransplant of a Scyment of Half of the Central Portion of the Injurcd Norie into the Gap.-There were sixteen experiments in this series which are recorded in Table 3 . 


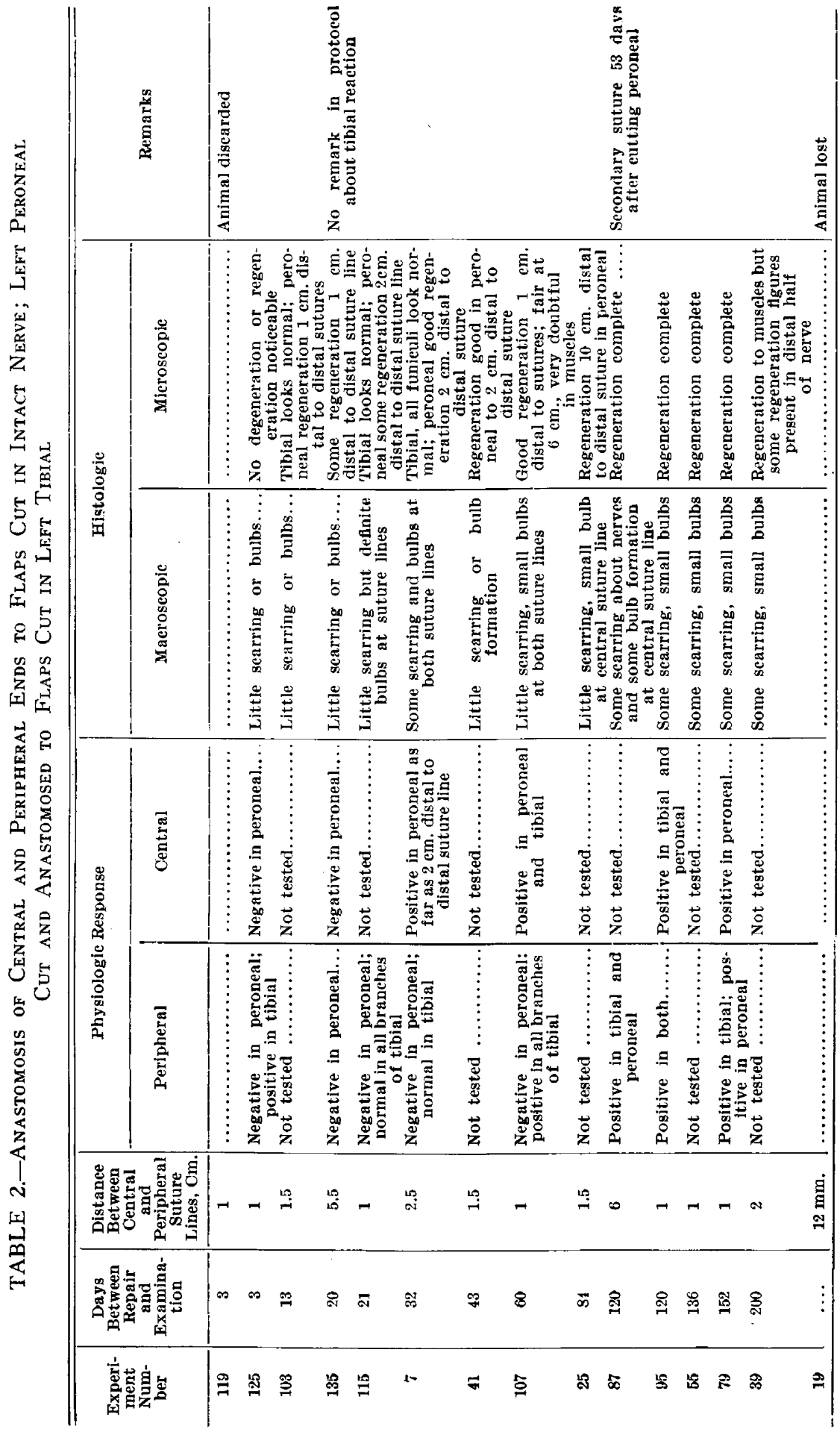




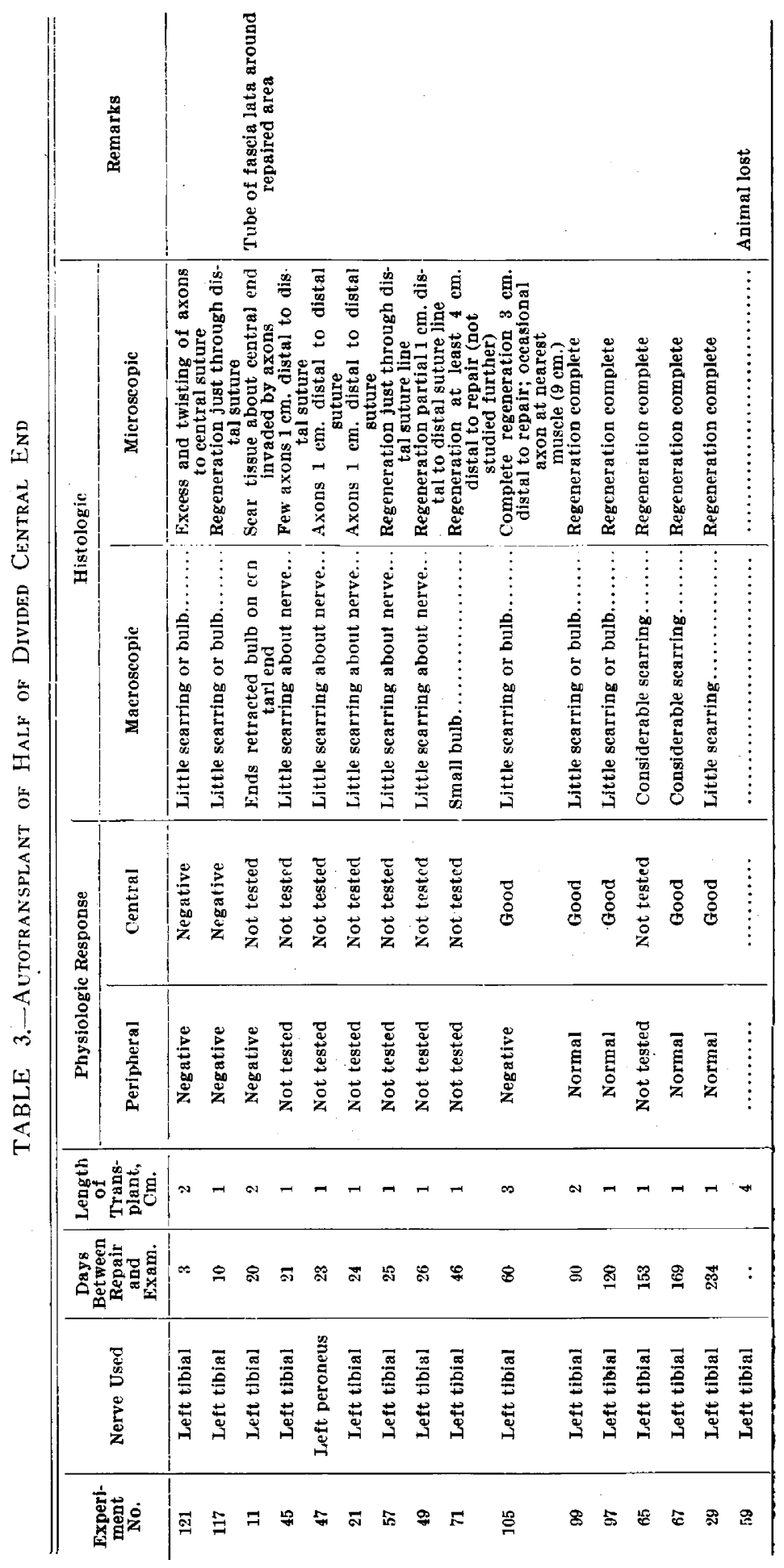


1. Physiologic-(a) As judged by the return of function, complete regeneration was observed about as rapidly as after the other methods of repair (ninety days).

(b) The central physiologic response was always present by the sixtieth day after the suture. How much earlier than this it was present we were unable to determine in this series as none of the nerves were tested physiologically before that time, except three and ten days after repair, when it had not yet appeared.

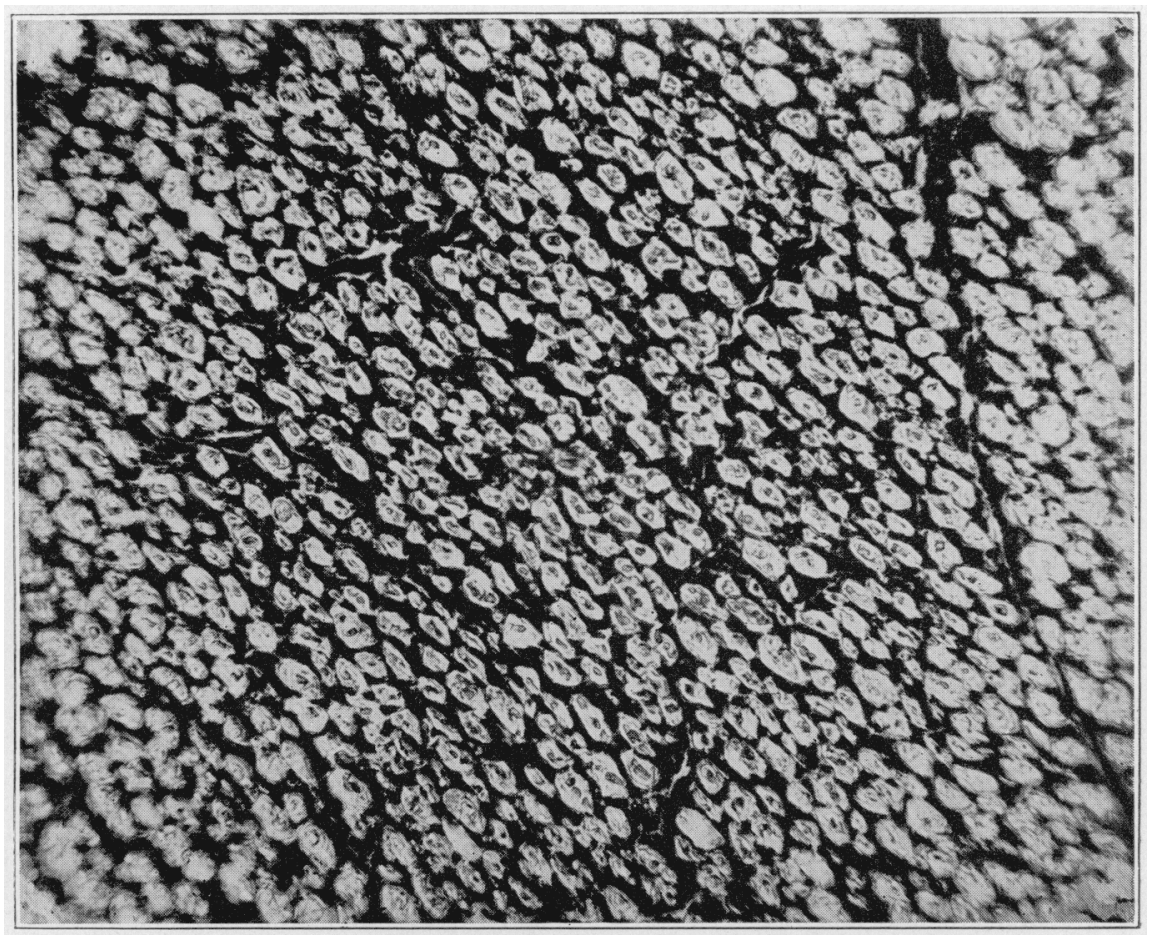

Fig. 8.-Cross-section of tibial nerve distal to auto-autotransplant five months after repair: all the medullary spaces are filled with axis cylinders but there is no excess of axis cylinders as in Figure 7.

(i) Peripheral response when it clicl appear was as active in one branch as in another, showing that regeneration was occurring throughout the nerve.

2. Histologically-- Axis cylinders grow from every point where they have been cut; but most of the fibers that get to the peripheral portion of the nerve grow through the autotransplant from those axis cylinders which lie in direct contact with the transplant. Some of the fibers grow down between the funiculi of the autotransplant and reach the peripheral end of the nerve. Some fibers were observed growing from the central 
end of the nerve from which the autotraibslant had been removed. These fibers grow along the nerve as well ats the transplant and reach the peripheral end of the nerve; but as there is some neuroma formation at that point, many of the axons never get through. Cross-sections were taken from the nerve where the tmansplant hat been removed (Fig. 3h), from the transplant i and both were compared with crosssections through a and $d$. These showed that the number of axis cylinders in the transpam was far greater than in half the original

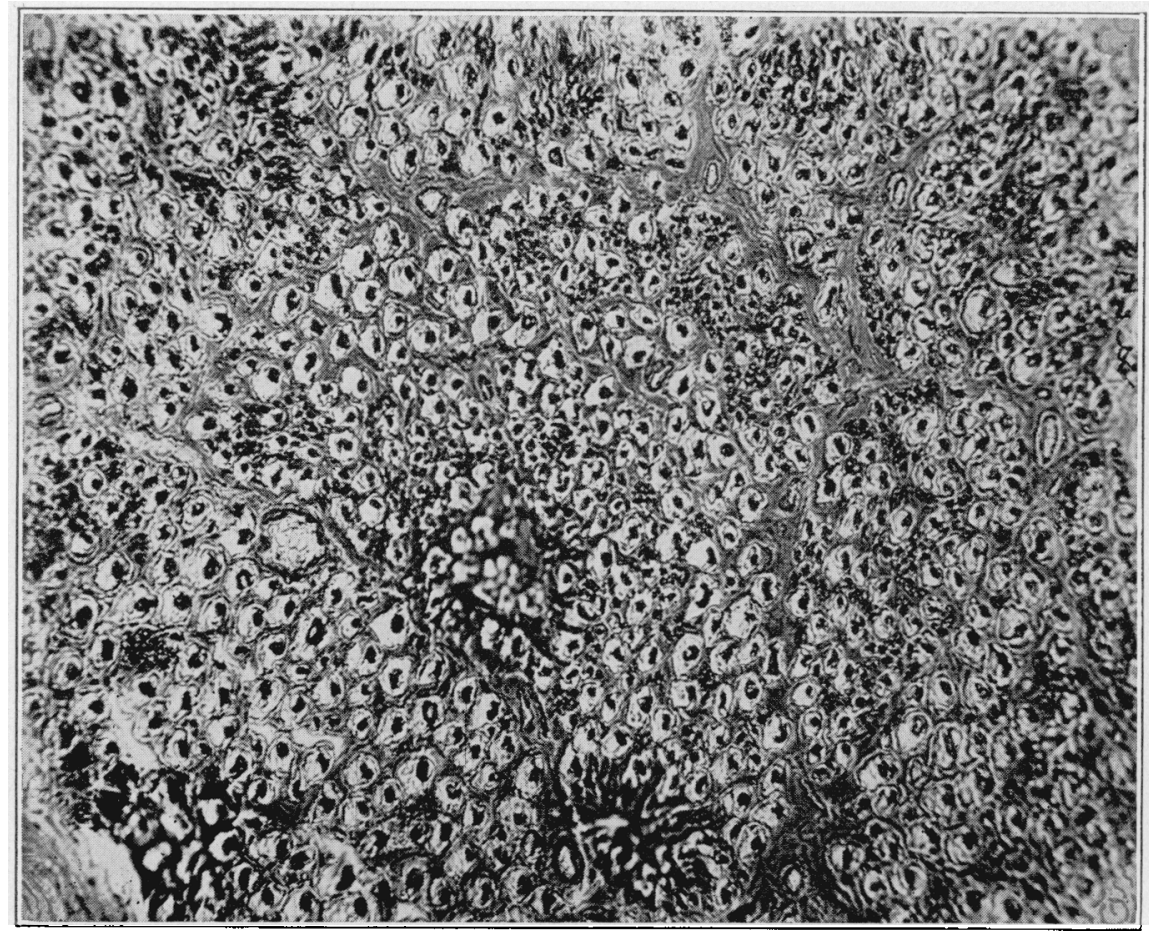

Fig. 9.-Cross-section of peroneal nerve central to double implantation showing the appearance of a normal nerve with well formed medullary spaces and large mumber of nonmedillated filbers.

nerve, and. though not actually counted, approximated the number of axis cylinclers in the normal nerve. All the medullary tubes in the peripheral portion of the nerve after complete regeneration has taken place are completely filled with axis cylinders (Fig. $s$ ). There is a marked overproduction of axis cylinders. for some of the medullary tubes contain several axis cylinders, and in some cases as many as five. This overproduction is striking at the end of three months; but when such nerves are studied after a five months period, the nerve looks normal, and evidently the surplus number of axons have disappeared. As 
was to be expected, a moderate amount of neuroma formation was observed both at the point where the transplant was removed and also at the distal suture line. A most interesting finding has been that nerves, when they first give a normal physiologic response after regeneration, histologically do not look normal (Figs. 7 and 9). The clear medullated sheaths are not present; but from six to eight weeks after that, such a nerve looks normal. This would indicate clearly that a motor nerve may functionate before it has regained its normal histologic appearance.

\section{DISCUSSION OF THE MERITS OF VARIOUS TYPES OF OPERATION FOR BRIDGING NERVE DEFECTS}

Our work has convinced us that any type of tissue other than nerve tissue used to bridge a nerve defect is, as a rule, unsatisfactory. This is merely confirmatory of what other observers have noted.

TABLE 4.-Primary End-to-End Suture

\begin{tabular}{|c|c|c|c|c|c|}
\hline \multirow{2}{*}{$\begin{array}{c}\text { Experi- } \\
\text { ment } \\
\text { No. }\end{array}$} & \multirow{2}{*}{$\begin{array}{c}\text { Days } \\
\text { Between } \\
\text { Repair } \\
\text { and } \\
\text { Exami- } \\
\text { nation }\end{array}$} & \multicolumn{2}{|c|}{ Physiologic Response } & \multicolumn{2}{|r|}{ Histologic } \\
\hline & & Peripheral & Central & Macroscopic & Mieroscopic \\
\hline 33 & 20 & Not tested & Not tested & Little searring or & $\begin{array}{l}\text { Regeneration } \mathrm{com} \text { p let } \\
\text { through suture line and fair } \\
2 \mathrm{~cm} \text {. distal }\end{array}$ \\
\hline 93 & 32 & Negative & $\begin{array}{l}\text { Pos. } 2 \mathrm{~cm} . \\
\text { distal to } \\
\text { suture line }\end{array}$ & $\begin{array}{l}\text { Little scarring and } \\
\text { small bulb }\end{array}$ & $\begin{array}{l}\text { Regeneration partial } 4 \mathrm{~cm} \text {. } \\
\text { distal to suture line }\end{array}$ \\
\hline 89 & 150 & Positive & Not tested & $\begin{array}{l}\text { Little searring and } \\
\text { small bulb }\end{array}$ & Regeneration complete \\
\hline 69 & 157 & Positive & $\begin{array}{l}\text { Negative } \\
\text { (anesthetic } \\
\text { deep) }\end{array}$ & $\begin{array}{l}\text { Little scarring and } \\
\text { small bulb } \\
\text {. }\end{array}$ & $\begin{array}{l}\text { Regeneration complete } 6 \mathrm{~cm} \text {. } \\
\text { distal (not studied farther); } \\
\text { some tendency to neuroma } \\
\text { formation at suture line }\end{array}$ \\
\hline 73 & 161 & Positive & Positive & $\begin{array}{l}\text { Little scarring and } \\
\text { small bulb }\end{array}$ & $\begin{array}{l}\text { Iormation at suture line } \\
\text { Regeneration complete }\end{array}$ \\
\hline $9 \mathrm{I}$ & 240 & Positive & Not tested & $\begin{array}{l}\text { Little scarring and } \\
\text { small bulb }\end{array}$ & $\begin{array}{l}\text { Regeneration complete, some } \\
\text { neuroma formation at su- } \\
\text { ture line }\end{array}$ \\
\hline
\end{tabular}

The type of repair that is most satisfactory for bridging defects so large that end-to-end anastomosis is not possible is the implantation of the central and peripheral ends of the nerve into an adjacent healthy nerve. Such a procedure in dogs gave a very satisfactory result and did not interfere with the function of the healthy nerve. When the gap was $2 \mathrm{~cm}$. or less many fibers from the central end grew into the peripheral end of the nerve. The larger the gap, the fewer fibers from the central end grew into the peripheral end; but some could always be traced into the peripheral stump and also into the normal nerve. As the maximum source of new axis cylinders is always desirable, this procedure should always be followed regardless of the size of the gap. There are two conditions in which the double implantation method is impracticable. One of these is encountered when the severed nerve is 
larger than the nerve into which an implantation could be made. The other condition occurs when there is no adjacent nerve available. In both these cases the method of auto-autotransplant is preferable.

The second type of anastomosis we have described has no advantages over the foregoing, either as to rate of regeneration, completeness of recovery or central fibers connecting with the distal end. It has the great disadvantage that much more injury is done to the normal nerve and there is more tendency to neuroma formation.

The method of auto-autotransplant described in this communication has the advantage that no normal nerve has to be destroyed and that it can all be carried out in one operative field. The results, in dogs, seem at least as good as those obtained by Huber's " autotransplant.

\section{GENERAL CONSIDERATIONS}

In every type of nerve suture, no matter how perfect the approximation is, there are whorls as the fibers grow out, so that corresponding fibers do not join, consequently some reeducation is always necessary. The objection that one might expect would be raised to the removal of part of a nerve is that certain funiculi going to certain muscle groups would thereby be injured or destroyed. The existence of internal plexuses in nerves, which has been the thesis of the work of Dustin, ${ }^{14}$ Heinemann, ${ }^{15}$ Langley and Hashimotto ${ }^{8}$ and most recently McKinley, ${ }^{16}$ disposes of this objection.

Our experiments lend support to this contention. Cross-sections of the sciatic nerve trunk, taken at $3 \mathrm{~mm}$. intervals, showed a variation in the number and size of the funiculi. This variation in number was as follows: three, seven, seven, four, three. Cross-sections of the posterior tibial nerve of a man were shrunk to such an extent by the fixative that accurate counts were not possible; but here also a marked variation in the number of funiculi at different levels was noted.

As further evidence bearing on this question we wish to point out that after cutting about one third of the diameter of the tibial nerve all the muscles supplied by the nerve reacted when each nerve branch to each group of muscles was stimulated. Whether there was any sensory impairment, of course, could not be determined on animals. Furthermore, a cross-section of the nerve below the point of section studied after degeneration was complete showed that the degenerated

14. Dustin, A. P.: Les lesions post traumatiques des nerfs contribution a l'histopathologie du systeme nerveux peripherique chez. l'homme, Ambulance de "L'Ocean," La Panne Extrait du fascicule II, December, 1917.

15. Heinemann, O.: Weitere Untersuchungen über den inneren Bau der grossen Nervenstämme, Arch. f. klin. Chir. 109:121, 1917.

16. McKinley, J. C.: The Intraneural Plexus of Fasciculi and Fibers in the Sciatic Nerwe, Arch. Neurol. \& Psychiat. 6:377 (Oct.) 1921. 
niber were sattered thronghout the nerve and did not crous one poriton wi the nerve as they should have if the fithers travel down a nerve in the same rectors.

Secontlary sutures made several month- after injury are as successful as primary sutures if the funiculi are hrought inde jerfect approximation withoul a connective tissue batrier. The physologic recovery was smewhat sower than in a prinary suture. Ne have been mable we efermine any reason for this.

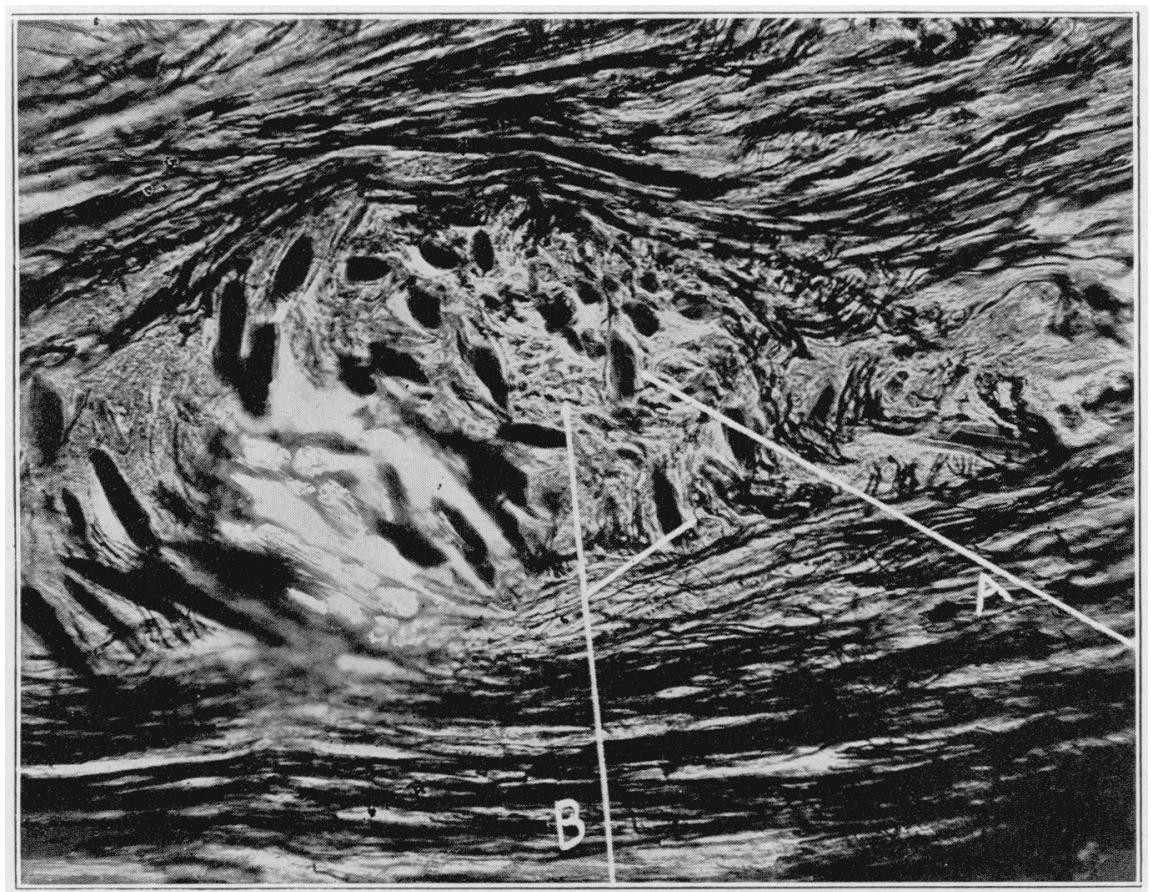

Fig. 10.-Silk suture with regenerated axis cylinders passing between the strancls of silk: A, silk; $R$, axis cylinclers.

Injection of abolute alcohol into the cut tund of a nerve reduced the tendency to neuromat formation in two experiments and to some extent in a third: but we were unable to obalin a picture similar to that obtained by Lewis and Huber ${ }^{3}$ in rablith. ()ur observations tend to show that the injection of abolute alcohol doren not completely prerent neuroma formation, though it does inhibit it. Injection of alcohol into the nerve trunk at the site of suture with the idea of preventing neuroma formation seemed of no value. thomgl it did not interfere

17. Lewis, Dean, and Huher. C. C.: Amputation Neuromas: The ir Derelop-

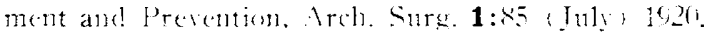


with the process of regeneration or prolong this process. The distortion of axons and interference with their growth at the site of suture is due to those factors that have been emphasized in the publications that have appeared in the last few years. Connective tissue is the great obstacle, and anything that may increase the formation of scar tissue is to be avoided. Occasionally, in the larger human nerves, bleeding from a small vessel is very troublesome and cannot be stopped by the application of heat. In such cases, rather than leave a fine ligature in the center of the regenerating nerve, we have for some years distended the end of the nerve with salt solution. Another and most important factor in getting good regeneration is the accurate approximation of the nerve ends so that the exposed nerve ends come in contact. To accomplish this most perfectly, sutures, as far as possible, should be placed in the perineural tissue and not through the fasciculi. We are convinced that sewing individual fasciculi together is a physical impossibility as well as not being absolutely necessary. In this connection, it may be well to emphasize again that extremely fine silk heals in with far less reaction than does catgut. It is quite astonishing to note that the reaction about silk is so slight that frequently axons can be seen growing between the strands of a silk ligature (Fig. 10).

\section{SUMMARY AND CONCLUSIONS}

1. Three methods of bridging defects in nerves have been studied by a combination of physiologic and histologic methods.

2. It has been shown that nerve fibers will grow down the trunk of a healthy nerve through a longitudinal incision without impairing its function and part of the fibers connect up with the peripheral end. It is, therefore, of distinct advantage to implant the central end of a cut nerve as well as the peripheral end.

3. On account of the branching of regenerating fibers, enough axons are produced when a nerve is cut longitudinally to fill the sheaths in the implanted nerve, indicating that in a nerve anastomosis, an end-to-side implantation is perfectly satisfactory. This confirms our clinical experience. We have for years practiced this method of anastomosis in faciohypoglossal anastomosis.

4. The test described by one of us (Malone) for determining that nerve fibers have grown across a point of suture has proved a valuable aid in determining at an early date whether or not a nerve is regenerating.

5. The study of cross-sections of nerves as well as the results following the method of auto-autotransplant described in this paper throw doubt on, and we believe disprove, the contention that peripheral nerves have an internal topography as maintained by Stoffel. 
6. Though absolute alcohol may inhibit to some extent the formation of neuromas, it does not absolutely prevent them.

7. The most important factor in a successful nerve anastomosis is the accurate approximation of the nerve ends so that there is no tissue between them which may interfere with the regeneration of the fibers. Every effort, of course, should always be made to bring them together in their original anatomic relation; but, owing to the presence of internal plexuses in nerves, it is not so essential as has been supposed heretofore. Whenever a nerve regenerates, whorls are formed at the regenerating end, consequently the central end of a fiber does not necessarily connect with its corresponding peripheral end.

8. The method of auto-autotransplant described in the foregoing pages for bridging defects too long to permit of an end-to-end anastomosis is to be preferred to cable autotransplants because no normal nerve has to be injured and the operation can be carried on in one field.

9. The method of choice for bridging large defects whenever possible is the double implantation method of anastomosis. Its advantage over the auto-autotransplant lies in the fact that some axis cylinders have only one suture line to grow through, while in the auto-autotransplant they all have to go through two suture lines. 